\title{
Selected programme methods of practical teaching - smart grid course as a case study
}

\author{
Robert Kucęba ${ }^{1, *}$ \\ ${ }^{1}$ Institute of Information Management Systems, Czestochowa University of Technology, Armii \\ Krajowej 19B Avenue, Częstochowa, Poland
}

\begin{abstract}
With reference to the subject matter defined in the present paper's title, the methods applied in the processes of formal practical teaching - programme methods, have been distinguished and aggregated on the basis of the research carried out within the ERASMUS+ project "The acceleration method of development of transversal competences in the students' practical training process". As a case study programme methods of formal teaching have been aggregated as well as informatic tools and applications used while developing the simulated by students in laboratory conditions, a virtual management environment of dispersed RES micro-installations, within the Smart Grid course included into the area of prosumer energy. This simulator reflects the functional and logical structure of the Virtual Power Plant, which integrates the prosumer energy sources.
\end{abstract}

\section{Introduction}

Formal teaching at higher education institutions (public, non-public and community ones) is usually a formalized institutional form $[1,11]$, implemented according to programmes that enable to gain qualifications (knowledge, skills and competences), recognized by the legal system as well as on the labour market. Differentiated practical teaching methods are used in the formal teaching processes, which facilitate acquisition of knowledge and skills and their use in professional practice. Application of differentiated practical teaching methods in the teaching process, enables students to evaluate the usefulness of presented teaching content and developed competences in "professional life", also in creating and following the "professional career path". The portfolio of practical teaching methods in formal teaching includes primarily the methods: problem ones, activating ones, exposing ones, programme ones and practical ones. The method which is also frequently applied in formal teaching, not indicated in the distinguished categories of methods, is groupwork (in formalized student teams).

With reference to the subject matter defined in the present paper's title, the cognitive focus concerns the applied in formal processes of practical teaching - programme methods with the use of differentiated informatic tools and applications. E-learning tools are also commonly applied at higher education institutions (both off-line and on-line ones). In case of programme methods used in formal teaching processes, one can observe growing share

* Corresponding author: robertkuceba@wp.pl 
of mobile applications use. Basically, programme methods ensure that students can efficiently, frequently without time and space limitations, become acquainted with the teaching content. It should be also indicated that a dynamic growth of applying in laboratory classes programme methods with the use of simulation games can be observed (e.g. MMOG class ones - massively multiplayer online game). Frequently informatic simulators reflecting heterogeneous systems, environments in business practice, are also developed by students. As supplementary to the already mentioned programme methods of teaching the following ones are also used: brainstorming, observation, panel discussion, problem lecture [2].

\section{Interdyscyplinarity of prosumer energy}

The selection of prosumer energy as a new utilitarian and at the same time interdisciplinary profile in practical teaching is justified by the needs of the labour market without being limited to the European Union ones only. Prosumer energy as a stimulant of local new and simultaneously perspective social "green initiatives" in favour of sustainable development of regions [3, 4]. The justification of selecting prosumer energy in the theoretical grasp is the reference to the third prosumer wave according to A. Toffler. It should be stressed here that A. Toffler rejected the traditional concept of a passive consumer, indicating the development of an active one, involved in the search of the product which best meets their expectations [5]. According to the A. Toffler's theory prosumer energy should be defined as a transformation from energy products acquired from fossil fuels in centralized energy sources - towards energy chains of RES energy value, co-created in economic microspaces, generating economic, environmental and social benefits [5]. The new energy value chains stimulate new business models on the energy markets (the new paradigm) - moving away from centralized models towards decentralized ones [6].

Prosumer energy stimulates the demand for a new group of local entrepreneurship, new work posts - and thus, the demand for a new group of specialists and indirectly new interdisciplinary courses/specialties/profiles of studies, and what follows the demand for "professional prosumers". The abovementioned is also justified by the currently observed diffusion of new investments into RES micro-installations, growth of environmental awareness of heterogeneous investors, and thus, their conscious social and environmental responsibility.

In accordance with the aforementioned justification of interdisciplinary -the practical profile of „Prosumer Energy” is confirmed by the convergence of knowledge, skills, social competences in four areas: technical, economic, social and natural - where it seems reasonable to distinguish the environmental one $[3,7]$.

In particular, in the technical dimension - in the practical teaching processes, attention is paid to diversity of energy sources in local perspectives, their dispersion and managing the dispersed prosumer energy infrastructure (e.g. micro- wind turbines, micro- biogas plants, photovoltaic and photothermal sources) [8]. Their indicated features include technological diversity, non-linear availability and the possibility of energy value growth that is produced, e.g. in RES micro-installations, through integration (also with the energy receivers on the side of prosumers) in the virtual environment of Smart Grid intelligent networks.

In the economic dimension the considered feature include: regional specialisation, proenvironmental investments, pollution reduction including creation of low emission/smog, incorporation of external costs into the prices of fuels and secondary energy, low cost and marginal costs of investments.

In the social dimension in turn, social competences are shaped in the practical teaching processes in the scope of: autonomous energy acquisition, change of energy consumption 
culture (change of energy consumers behaviours - adjusting own energy needs to the availability of non-linear RES sources) and stimulation of the willingness to pay (CostBenefit Analysis) - frequently incurring larger costs resulting from additional external (environmental) costs.

In the environmental dimension the students acquire knowledge and develop skills in the scope of perceiving the relations between prosumer energy diffusion and natural environment pollution reduction. This concerns in particular the ability to analyse, measure, monitor and interpret air pollution indexes.

The abovementioned dimensions confirming the utility and interdisciplinarity of prosumer energy, as well as the demand on the labour market for a new group of specialists, justify the introduction into the didactic offer of Higher Education Institutions a new course or specialty "Prosumer Energy". The course/specialty "Prosumer Energy" has also been included into the educational offer of the universities that cooperate in carrying out the ERASMUS project "The acceleration method of development of transversal competences in the students' practical training process" [2]. It should be indicated here that this course/specialty has been introduced at technical faculties, especially Electrical Faculties.

\section{PRACTICAL TEACHING METHODS OF DISPERSED RES MICRO-INSTALLATIONS MANAGEMENT}

Taking into consideration the utilitarian and interdisciplinary dimensions of prosumer energy at the Management Faculty (social sciences) of Czestochowa University of Technology/Poland, the Authors of the present paper have started the specialty - "Energy and Environmental Management" within the course Spatial Economy, directly connected with the prosumer energy profile. This specialty comprises issues in the scope of energy and environmental management in territorial government units, as well as business organizations. It prepares substantively and practically specialists in the scope of energy and environmental management (with particular consideration of prosumer energy), in this planning, optimizing and balancing energy needs, designing prosumer energy systems in territorial government units, manufacturing and service providing enterprises or public utility units, e.g. healthcare.

A measurable goal of practical teaching within the subject Smart Grid is consolidation of knowledge, skills and competences in the area of prosumer energy and carrying out own projects reflecting actual conditions of managing these sources and energy receivers on the prosumer side. Smart Grid classes take place in a computer laboratory, primarily with the use of programme methods of practical teaching.

In the present point of the paper the Authors in a synthetic way present the course of project classes within the subject Smart Grid with the use of various practical teaching methods, in particular programme methods and tools. The schedule of the classes is assigned with reference to the designed by the students, in laboratory conditions of the Management Faculty, three layers of Smart Grid [6] - which reflect the structure of the Virtual Power Plant integrating prosumer energy sources $[9,10]$.

\section{STAGE I - SELECTION OF PROSUMER TECHNOLOGIES IN THE PROSUMER TECHNOLOGY LAYER}

PRACTICAL TEACHING METHODS: group work, panel discussion or/and brainstorming with the participation of the lecturer.

REQUIREMENTS: theoretical background supplemented with a case study of good practices resulting from the knowledge, skills, competences acquired within the subjects of the specialty: Renewable and Dispersed Energy Systems, Energy Infrastructure Management, as well as Synergetics and Eco-innovations. 
IMPLEMENTATION (groups of 3-4 students): The first layer Prosumer Technology (PT) is determined in the actual Smart Grid structure as an operational one. In the first PT layer the students in the basis of a panel discussion or/and brainstorming with the participation of the lecturer select - at least two heterogenous prosumer micro-installations (in the laboratory conditions this usually concerns: micro- photovoltaic sources and microwind turbines) according to the criteria: demand for energy at the household where students reside and the local economic potential of RES "carriers" (on the basis of local reports concerning, e.g., wind speed or amount of sunlight). The task of the students at designing the simulator of the PT layer is also selection of electricity receivers (e.g. domestic appliances and intelligent vehicle charging systems: plug-in hybrid electric vehicle -PHEV - only as a design assumption), which can be controlled (e.g. with the use of the IoT technology) adjusting their work schedule to the availability of non-linear RES sources.

\section{STAGE II - SIMULATING PROCESSES IN THE SMART METERING LAYER}

PRACTICAL TEACHING METHODS: group work, programme methods: with the use of computer applications (in particular Google Drive, Google Spreadsheets).

REQUIREMENTS: a) theoretical background supplemented with a case study of good practices resulting from knowledge, skills, competences acquired within general majors subjects: Statistics and Econometry, and the specialty subjects: Renewable and Dispersed Energy Systems, Energy Infrastructure Management, as well as Synergetics and Ecoinnovations; b) a project of the Prosumer Technology layer.

IMPLEMENTATION: (project teams of 3-4 students): In the second layer of MicroSmart Grid - an analytic one, which is a simulation of Smart Metering - SM (in real conditions -metering infrastructure - bidirectional intelligent metres), students on the basis of the available power patterns of RES installations, depending on local daily changes of, for example, the amount of sunlight or/and wind speed, create in spreadsheets daily power characteristics of available energy sources - introduced in the first PT layer, e.g., for microphotovoltaic sources and micro- wind turbines. Another task of designing the SM layer is to elaborate the total daily power characteristics of available RES hybrid (aggregate daily availability of adopted in the project Prosumer RES micro-installations). Due to the limited in the laboratory conditions access to Intelligent Metering Infrastructure, the students perform in the period of seven days readings of energy consumption at one-hour intervals in their households (in real conditions of SM work the readings are performed at intervals not longer than 15 minutes). On the basis of the readings the students prepare in spreadsheets for all the days when the readings were performed, daily, calendar load characteristics (demand for electricity). Another task in simulating the SM layer is preparing the spreadsheet of daily, calendar characteristics of supply - available power of the micro-installation hybrid (the design assumption: repetition of the hybrid availability in subsequent days of measurements) and demand (real demand for energy in the given household) balancing.

\section{STAGE III - DEVELOPING A SIMULATOR OF THE SYSTEM TO MANAGE PROSUMER TECHNOLGY INFRASTRUCTURE}

PRACTICAL TEACHING METHODS: group work, programme methods: with the use of computer applications - in the cloud Google Drive: Google Spreadsheets and neural networks generator in the application environment STATISTICA NEURAL NETWORKS PL.

REQUIREMENTS: a) theoretical background supplemented with a case study of good practices resulting from knowledge, skills, competences acquired within general majors subjects: Statistics and Econometry, Economic Forecasting and the specialty subjects: Renewable and Dispersed Energy Systems, Energy Infrastructure Management, as well as Synergetics and Eco-innovations; b) a project of the Prosumer Technology layer; c) the project of Smart Metering layer. 
IMPLEMENTATION (coordinated cooperation of all project teams of 3-4 persons. Due to the population of the laboratory groups usually 5 project teams): In the real structure of this Smart Grid layer - Prosumer Technology Infrastructure Management Systems in the virtual environment support management of prosumer energy dispersed resources. This concerns planning, scheduling the work of energy receivers with reference to the availability of RES micro-installations. In order to settle the implementation of the energy and climate package, e.g. $3 \times 20$, amounts of generated energy from RES (available power and electricity generated in RES micro-installations) are aggregated in these systems.

The students using spreadsheets determine the indexes of air pollution reduction and reduced use of fossil fuels to produce the same amount of energy in RES microinstallations and thermal power plants. The students using spreadsheets, on the basis of historical supply-demand data, in this balanced one (data aggregated and visualized in the second layer of Smart Metering), design an analytic system, which generates forecasts of periodical availability and demand for electricity, in the adopted prosumer infrastructure. The forecasts are carried out in spreadsheets with the use of linear forecasting models: e.g. with the use of forecasting formulas according to: running average, forecasting models, ARMA and ARIMA models. Additionally, the forecasts are carried out with the use of nonlinear models generated in the neural networks environment STATISTICA NEURAL NETWORKS PL4. Non-linear models created by the students in this environment include: Multilayer Perceptrons (MLP), Kohonen Self-Organizing Feature Maps (KSO), Probabilistic Neural Networks (PNN), Generalized Regression Neural Networks (GRNN) and Linear Networks (LN). The developed forecasting models (linear and non-linear ones) are subject to verification (ex post) on the basis of relative and average square errors generated at the same time intervals. The goal of verifying the accuracy of the forecast is the selection of the final forecasting model.

The last element of the project is cumulating non-linear outputs of available power and the demand for energy generated by all project teams within the laboratory group of the students. A measurable result of such a cumulation is defining the amount of electricity generated in the virtual power plant (cumulated amount of electricity in RES microinstallations, adopted in the PT layer by particular project teams), aggregating the reduction size of the demand/purchase of electricity from the Energy System, as well as determining indexes of air pollution reduction. In particular, in the academic laboratory conditions of the Management Faculty this concerns reduction indexes of $\mathrm{CO}_{2}, \mathrm{NO}_{\mathrm{x}}$.

To sum up, on the basis of the evaluation of practical teaching methods, conducted among the students after the laboratory classes, it was concluded that the applied programme methods (even though the informatic tools portfolio was limited in the laboratory conditions of the University) supplemented with problem methods (e.g. panel discussion, brainstorming) or activating methods, in a synergic way influenced the level and results of the teaching process:

- profound, up-to-date knowledge in the scope of:

- prosumer energy - RES micro-installations,

- functions and structure of informatic decentralized systems of energy management;

- acquired skills and competences in the scope of:

- designing, implementing and optimizing Smart grid networks,

- generating and analysing the availability of energy sources and loads on the prosumer side,

- determining and interpreting indexes of greenhouse gases reduction and reduced use of primary fuels in prosumer energy,

- managing the energy demand and supply on the side of the prosumer,

- creative thinking and work in project teams. 


\section{Summary}

Diversifying the practical teaching methods, independent creation of procedures, determining the processes (e.g. managing the energy demand and supply in prosumer installations) and their migration to the virtual environment enables students to evaluate the usefulness of presented teaching content and developed competences in "professional life".

This is confirmed by the firs graduates of the specialty "Energy and Environmental Management", directly connected with the profile of prosumer energy. They indicate that the knowledge, acquired skills and competences in the scope of planning, designing, programming the procedures - managing the energy infrastructure, in this dispersed RES micro-installations place them very high on the labour market. On the basis of an analysis of professional career paths of the first graduates of this specialty (it should be stressed here that they are graduates of a non-technological faculty), 54\% of the researched population work or participate in professional internships in territorial government units - in the departments of energy management in territorial units. Diversification of practical teaching methods with the consideration of programme methods facilitates creating a "climate" for development of new groups of entrepreneurship, inspires the students to participate actively in didactic activities, establish their professional preferences and combine theoretical and practical knowledge.

\section{References}

1. A. Andrzejczak, Methodology of studying (2014)

2. The Project The acceleration method of development of transversal competences in the students' practical training process: ,"The report concerning applied teaching methods of transversal skills and methods of practical trainings" (Poznań, 2016)

3. R. Kucęba, L. Kiełtyka, Present Day Trends of Innovations (2013)

4. H. Son, T. Y. Kang, H. Kim and J. H. Roh, IEEE Transactions on Smart Grid, 2, 759-769 (2011)

5. A. Toffler, The Third Wave (1980)

6. J. Popczyk, Dispersed Energy (2011)

7. D. Niedziółka, Energetyka Prosumencka. Próba pierwszej konsolidacji (2014)

8. R. Kucęba and M. Bajor, Prosumer Energy. First Consolidation Attempt (2014)

9. R. Kucęba, Virtual power plant. Chosen aspects of organization and management of dispersed generation subjects (2011)

10. R. Kucęba, F. Bylok, A. Pabian, M. Zawada, Conference Proceedings ICSSAM and ISEPSS, 1040-1051 (2014)

11. A. Pacana, R. Ulewicz, Polish Journal of Management Studies 16, 165-174 (2017) 